\title{
Students' experiences with collaborative learning in asynchronous Computer-Supported Collaborative Learning environments
}

Citation for published version (APA):

Dewiyanti, S., Brand-Gruwel, S., Jochems, W., \& Broers, N. (2007). Students' experiences with collaborative learning in asynchronous Computer-Supported Collaborative Learning environments. Computers in Human Behavior, 23(1), 496-514. https://doi.org/10.1016/j.chb.2004.10.021

DOI:

10.1016/j.chb.2004.10.021

Document status and date:

Published: 01/01/2007

Document Version:

Peer reviewed version

Please check the document version of this publication:

- A submitted manuscript is the version of the article upon submission and before peer-review. There can be important differences between the submitted version and the official published version of record. People interested in the research are advised to contact the author for the final version of the publication, or visit the DOI to the publisher's website.

- The final author version and the galley proof are versions of the publication after peer review.

- The final published version features the final layout of the paper including the volume, issue and page numbers.

Link to publication

\section{General rights}

Copyright and moral rights for the publications made accessible in the public portal are retained by the authors and/or other copyright owners and it is a condition of accessing publications that users recognise and abide by the legal requirements associated with these rights.

- Users may download and print one copy of any publication from the public portal for the purpose of private study or research.

- You may not further distribute the material or use it for any profit-making activity or commercial gain

- You may freely distribute the URL identifying the publication in the public portal.

If the publication is distributed under the terms of Article 25fa of the Dutch Copyright Act, indicated by the "Taverne" license above, please follow below link for the End User Agreement:

https://www.ou.nl/taverne-agreement

Take down policy

If you believe that this document breaches copyright please contact us at:

pure-support@ou.nl

providing details and we will investigate your claim.

Downloaded from https://research.ou.nl/ on date: 26 Apr. 2023 
This is a pre-print of the article that was published as:

Dewiyanti, S., Brand-Gruwel, S., Jochems, W., \& Broers, N. (2007). Students experiences with collaborative learning in asynchronous computer-supported collaborative learning environments. Computers in Human Behavior, 23, 496-514.

Copyright Elsevier, available online at http://www.elsevier.com/wps/find/journaldescription.cws_home/759/description\#description

Students' experiences with collaborative learning in asynchronous computer-supported collaborative learning environments

Dewiyanti, S.*, Brand-Gruwel, S.*, Jochems, W.*, \& Broers \#

* Open University of he Netherlands, \# University of Maastricht 


\begin{abstract}
This chapter describes an explorative study carried out to gain response from distance students on their experiences with collaborative learning in asynchronous computersupported collaborative learning (CSCL) environments. In addition, this study also attempts to have a good grip of crucial aspects concerning collaborative learning. The study was undertaken among distance learners from the Open University of the Netherlands who were working in groups of four to eleven persons. During and after the course students' experiences with collaborative learning were measured and after the course also students' satisfaction with collaborative learning was assessed. The finding revealed that distance learners appreciate the opportunities to work collaboratively. They show positive experiences and are quite satisfied with collaborative learning. This study also explored individual as well as course characteristics that influenced aspects of collaborative learning, and also aspects of collaborative learning that influenced students' satisfaction. The findings suggested that a group product influences regulation of group processes and group cohesion influences students' satisfaction with collaborative learning.
\end{abstract}


Nowadays computer-supported collaborative learning (CSCL) environments are viewed as an important electronic learning medium for distance education. CSCL environments can be described as a context where the computer facilitates interactions among learners for acquisition of knowledge, skills and attitudes (Dillenbourg, 1999; Kaye, 1992; Koschman, 1996). Working together while accomplishing a task is seen as a characteristic of a powerful learning environment, aiming at active construction of knowledge (Van Merriënboer \& Paas, 2003). Through a process of interaction and negotiation students have an active and constructive role in the learning process.

Research in recent years has shown that CSCL environments have been used successfully to promote learning achievements in distance education. Harasim (1989) described the social, affective and cognitive benefits of collaborative group work for distance learners. From her study, she concluded that collaborative learning promotes more active and more effective learning for distance education. Hiltz (1995) also reported that students in collaborative learning conditions had more constructive learning processes and attained higher grades than students in other conditions. These environments provide distance learners the opportunity to work together and to practice critical reflection, conflict negotiation, and consensus building as in face-to-face learning environments. Besides, students are encouraged to exchange ideas, to share perspectives and arguments, and to use previous knowledge or experience in order to decide on the best solution for the problem to be solved. So, the use of CSCL environments can both help to overcome physical isolation between students and teachers, and help to improve learning.

CSCL environments are often promoted as an open, safe, and trustable learning environment that allows equal opportunities for learners to participate without the limitation on knowledge levels (Scardamalia \& Bereiter, 1994). These learning environments stimulate students to express their ideas and arguments without any feeling to be penalized or ridiculed (Rowntree, 1992). In a CSCL environment students have the opportunity to take over some control of their own learning and to be active learners who are not only absorbing information but also connecting previous knowledge and new information to gain a deeper level of understanding. The use of an asynchronous CSCL environment is recommended for distance education above a synchronous CSCL environment because it offers flexibility in time to read, to reflect and to compose the responses (Abrami \& Bures, 1996).

Students' participation in collaborative learning is seen as the interaction and the contribution of group members when they are collaborating to solve a problem or to accomplish a task. Various elements in an asynchronous CSCL environment may influence students' participation. The important elements are course characteristics, individual characteristics, different aspects of collaborative learning and satisfaction.

Course characteristics. Group size, the type of product (individual or group product), and teacher involvement are considered to be essential characteristics of courses in CSCL environments. Figure 1 in chapter 2 describes these characteristics as conditions for positive interaction in the collaboration process. Group size influences students participation in collaboration substantially 
(Johnson \& Johnson, 1994; Shaw, 1981). Collaborating in small groups makes it easier to stimulate non-active participants, promotes a higher sense of presence and engagement, and increases the individual contributions (Bates, 1995; Hammond, 2000; Kaye, 1992; Wegerif, 1998). Regarding the type of product, Cohen (1994) argued that the task assigned to a group determines how group members interact. Courses that encourage collaboration in general show that the students become more active participants in the learning process when the task requires a high level of collaboration. A high-level collaborative task, for example requesting a group product, requires group members not only to share information or to determine how to divide their labours, but also to discuss how to proceed as a group. On the contrary, a task with low level of collaboration, for example, requesting submission of individual report, lacks of group interdependency that might hinder group members to collaborate while accomplishing the task (Johnson et al., 1994). Distance students usually less depend on the teacher and have more freedom to structure their own learning. So, in distance education teacher involvement in collaborative learning is limited.

Individual characteristics. Individual characteristics such as students' ideas about collaborative learning and students' experience with the use of technology might inhibit or promote their participation in the collaborative learning processes (Kagan, 1994). For example, in CSCL environments students are required to communicate by using text-based communication tool. A lack of experience of using text-based communication might influence students participation in their groups (Ross, 1996; Zafeiriou, Nunes, \& Ford, 2001).

Collaboration process. The process of collaboration itself is the heart of CSCL (see figure 1 in chapter 2). Collaboration refers to activities that are related to how the group is functioning in accomplishing a task. Within collaborative learning, the responsibility for learning shifts from the teacher to the group members (Bruffee, 1995). This provides an opportunity for the group members to regulate their collaboration process. As a group, they should plan the working process together and make sure that the process will be goal directed. In order to achieve the learning goals group members need to support each other. They should discuss the learning content in depth and maintain the ongoing collaboration process. Determining strategy, contributing ideas, handling internal conflicts and monitoring group processes are important aspects within the collaborative learning. Thus, in order to reach the learning goals all group members have the responsibility to participate in the collaboration process.

Satisfaction with collaborative learning. Students' satisfaction with collaborative learning is an outcome of the collaboration process and can be described as the degree to which a student feels a positive association with his or her own collaborative learning experiences. Students' satisfaction can have repercussions on how students work together, such as whether everyone does his/her part of the work, whether group members can work with each other, whether group members remain on the task (no fighting, no fooling around or too much chatting), and whether there is a good working atmosphere in the group (Gunawardena et al., 2001). Although several studies (Harasim, 2001; Hiltz, 
1995) have reported the benefits of collaborative learning for distance learners, still there are many questions surrounded the implementation of collaborative learning in distance education. Little is known on students' experiences during the collaboration process in asynchronous CSCL environments. Understanding students' experiences is important because this might help designers to provide specific instructions to enhance the quality of the learning process.

This chapter describes an explorative study carried out to gain response from distance learners on how they experience collaborative learning in asynchronous CSCL environments and attempts to have a good grip of the described crucial aspects concerning collaborative learning. In the end, the findings of this study should provide practical implications for supporting effective learning in asynchronous CSCL environments.

The specific questions addressed in this study were as follows:

1. How do distance students experience collaborative learning in asynchronous CSCL environments?

2. Are distance students, who in general are unfamiliar to each other, satisfied with collaborative learning in asynchronous CSCL environments?

3. To what extent do the individual characteristics and the course characteristics influence students' experiences with collaborative learning?

4. What aspects with respect to collaboration do influence students' satisfaction?

5. How do students actually collaborate in an asynchronous CSCL-environment?

\section{Method}

\section{Participants}

Students from five distance learning courses of the Open University of the Netherlands volunteered for this study. Participants were asked to complete three surveys (before, during and after the course). Respondents at the first survey were 112 students (76 men and 36 women). Furthermore, 51 participants responded to the second survey ( 34 men and 17 women). Finally, 67 participants (47 men and 20 women) responded to the last survey. Table 1 summarises the numbers of participants for each course across the surveys.

Table 1

Number of participants for each course across the surveys

\begin{tabular}{lccc}
\hline & \multicolumn{3}{c}{ Surveys } \\
\cline { 2 - 4 } Course & Before the course & During the course & After the course \\
\hline Change management & 30 & 13 & 13 \\
Law & 16 & 15 & 15 \\
Informatics* & 19 & - & 15 \\
Management science & 33 & 8 & 16 \\
Environmental science & 14 & 15 & 8 \\
\hline
\end{tabular}


* Because of the short duration of the informatics course, the participants from this course only responsed at the first and the third survey. 


\section{Materials}

Courses

All the courses required students to work in groups and to submit either a group product or an individual product. All the courses applied asynchronous CSCL environment. The descriptions of the course characteristics are summarised in Table 2.

Table 2

Course characteristics

\begin{tabular}{lccc}
\hline \multicolumn{1}{c}{ Course } & Period & Group members & Type of product \\
\hline Change management & 25 weeks & $3-4$ & Individual product \\
Law & 24 weeks & 4 & Group product \\
Informatics & 2 weeks & 4 & Group product \\
Management science & 20 weeks & $8-11$ & Individual product \\
Environmental science & 17 weeks & 4 & Group product \\
\hline
\end{tabular}

\section{Questionnaire on individual characteristics}

The individual characteristics questionnaire consisted of five scales. The first scale assessed student attitude towards collaboration (Attitude Towards Collaboration, 12 items, Cronbach's $\alpha=.87$ ), e.g., "I find that it is interesting to work together in a group". The second scale gathered information about individual activities in a group (Group Activity, 6 items, Cronbach's $\alpha=.82$ ), e.g., "I like to take the initiative". The third scale was intent on get information on students familiarity with text-based communication (Perceived Text-based Communication, 4 items, Cronbach's $\alpha=.86$ ), e.g., "Discussion group is a pleasant way to communicate". The fourth scale aimed at gaining information on student prior knowledge (Prior Knowledge, 4 items, Cronbach's $\alpha=.76$ ), e.g.," I can explain to other students about this subject", and, the last scale assessed students opinion on using Internet (Opinion on Using Internet, 5 items, Cronbach's $\alpha=.75$ ), e.g., "Internet was a pleasant way to get information all over the world". The format of all items is a Likert-type scale, ranging from 1 (strongly disagree) to 5 (strongly agree).

\section{Questionnaire on collaborative learning}

Students' experiences with collaborative learning were assessed with six scales (23 items all in) developed for the purpose of the present study and three existing scales. The six scales were (a) Monitoring Working Procedure (8 items, Cronbach's $\alpha=.87)$ e.g., "I remind group member who do not work together properly", (b) Participation (5 items, Cronbach's $\alpha=.85$ ), e.g. "All group members participate in discussions to reach a consensus", (c) Monitoring Group Progress (5 items, Cronbach's $\alpha=.83$ ) e.g., "I have responsibility to maintain our plan", (d) Helping Each Other (3 items, Cronbach's $\alpha=.70$ ), e.g., "I help other group member who have difficulty to understand the learning material" (e) Giving Feedback ( 2 items, Cronbach's $\alpha=.75$ ) e.g., "I constantly gave feedback to other 
group member works", and (f) Need to be Monitored (2 items, Cronbach's $\alpha=.68$ ) e.g., "I feel pleasant if someone reminds me about the deadline". Then, three existing scales assessed Team Development, Intra-group Conflict and Task Strategy. The Team Development scale was adapted from Savicki, Kelley, \& Lingenfelter (1996) to assess the degree of cohesion that was achieved while group members have been working together (11 items, Cronbach's $\alpha=.91$ ), e.g., "All group members understand the group goals and were committed to them". The scale Intra-group Conflict consisted of seven items. Items in this scale were adapted from Saavedra, Early, \& Van Dyne (1993) and measured the degree of conflicts in a group (7 items, Cronbach's $\alpha=.72$ ), e.g., "There was a lot of tension among people in our group". The Task Strategy scale was adapted from Saavedra et al. (1993) and assessed the decisions and choices made by a group while completing the task ( 7 items, Cronbach's $\alpha$ $=.81$ ), e.g., "Our group developed a good strategy for doing the tasks". The format of all items was a Likert-type scale, ranging from 1 (strongly disagree) to 5 (strongly agree).

\section{Questionnaire on satisfaction with collaborative learning}

This questionnaire consisted of three scales that measured (a) Satisfaction with Group Members Attitudes ( 6 items, Cronbach's $\alpha=.86$ ), e.g., “All group members can get along well”, (b) Satisfaction with Learning in the Group (5 items, Cronbach's $\alpha=.87$ ), e.g., "I learn a lot from other group members", and (c) Satisfaction with Group Working (4 items, Cronbach's $\alpha=.82$ ), e.g., "I feel pleasant to work together in the group to solve a task". In addition students' satisfaction over their final product was measured with a single item "I am satisfied with the final product". The format of all items was a Likert-type scale, ranging from 1 (strongly disagree) to 5 (strongly agree).

\section{Content analysis}

Content analysis aimed to gain more detailed understanding of learners' activities during collaborative learning. Based on previous studies in analysing students' messages (Henri, 1992; van Boxtel, van der Linden, \& Kanselaar, 2000; Veerman, 2000; Veldhuis-Diermanse, 2002), a coding scheme was developed to analyse students' messages. The coding scheme consisted of six functional dimensions and 19 specific categories (Table 3).

The Regulation dimension consists of contribution about coordinating activities of learners, e.g. "I propose that we should finish the draft within two weeks". The Consensus dimension consists approval expressions of an idea, e.g. "Yes, I agree" or "That is absolutely correct". The Conflict dimension indicates disagreement of learners activities, e.g. "I do not like the way you work". The Content dimension includes contributions about activities to gain domain knowledge, e.g. "I do not understand what you mean. Can you explain it?". The Social dimension contains emotional expressions and non-task information, e.g. "You did a great work" or "I had a nice weekend". The Technology dimension describes expressions about the use of computer, e.g. "How can I attach a document". 
Table 3

Coding scheme

\begin{tabular}{ll}
\hline Dimension & Category \\
\hline Regulation & Orientation \\
& Plan \\
& Meflection \\
& Monitoring general \\
& Monitoring working progress \\
& Monitoring participation \\
\hline Consensus & Reach consensus \\
& Try to reach consensus \\
\hline Conflict & Conflict \\
\hline Content & Ask \\
& Explain \\
& Argue \\
& Product \\
& External resources \\
\hline Social & Negative emotion \\
& Positive emotion \\
\hline Technology & Off task \\
\hline
\end{tabular}

In order to apply this coding scheme, each message was broken down into manageable items, so-called units, for subsequent allocation into relevant categories. Each unit was assigned only to one category. Because one message might contain more than one topic, the base unit of analysis was sentences within one message. When two continuous sentences dealt with the same topic, they were counted as one unit. And, when one sentence contained two topics, it was counted as two separate units.

Using this coding scheme, two raters independently segmented the messages and classified the units into the appropriate category. If a unit could not be categorised (e.g. ambiguous statements) then the rest category was used.

Coding messages was completed in two steps to establish a good reliability between the raters. In the beginning, ten postings transcripts were randomly selected and were coded independently by the two raters. Then the codes were compared to reach consensus on the use of the categories. This process allowed for the coding categories to be further refined and for the raters to discuss ambiguity or disagreement until consensus was reached. The first training session between two raters across all 
discourse categories reached a Cohen's kappa value of .48. After an intensive training, Cohen's kappa reached value of .62. Then one rater coded the remaining messages.

\section{Design and procedure}

The surveys were administered in the period of six months (dependent on the courses starting dates and the duration of the courses involved). All surveys were distributed via e-mail, regular mail or at a face-to-face meeting. Participants were asked to complete the survey individually and to return them to the researcher via electronic mail or regular post. After one week a reminder was sent to the non-respondents.

Three surveys concerning individual characteristics, experiences and satisfaction with collaborative learning were administered before, during and after the course. Table 4 provides an overview of the different measurements and moments of surveys administration.

Table 4

Design of the study

\begin{tabular}{lccc}
\hline & \multicolumn{3}{c}{ Surveys } \\
\cline { 2 - 4 } Course & Before & During & After \\
\hline Change management & $\mathrm{O} 1$ & $\mathrm{O} 2$ & $\mathrm{O} 2+\mathrm{O} 3$ \\
Law & $\mathrm{O} 1$ & $\mathrm{O} 2$ & $\mathrm{O} 2+\mathrm{O} 3+\mathrm{O} 4$ \\
Informatics & $\mathrm{O} 1$ & - & $\mathrm{O} 2+\mathrm{O} 3$ \\
Management science & $\mathrm{O} 1$ & $\mathrm{O} 2$ & $\mathrm{O} 2+\mathrm{O} 3$ \\
Environmental science & $\mathrm{O} 1$ & $\mathrm{O} 2$ & $\mathrm{O} 2+\mathrm{O} 3$ \\
\hline
\end{tabular}

$\mathrm{O} 1=$ Questionnaire on individual characteristics

$\mathrm{O} 2=$ Questionnaire on collaborative learning

$\mathrm{O} 3=$ Questionnaire on satisfaction with collaborative learning

$\mathrm{O} 4=$ Content analysis of one of the five groups from the Law course

The first survey administered before the courses started was intended to get information on students' characteristics. The second survey was designed to retrieve information on students' experiences with collaborative learning and was administered halfway the course. The third survey was designed to gain information on students' experiences with collaborative learning as well as on students' satisfaction with collaborative learning. This survey was administered after the course was completed. In addition, messages from one of five groups from the Law course was analysed as a sample to explore activities while students were working in the group.

\section{Results}

Individual characteristics 
Before giving the results concerning the research questions, a closer look is taken at the characteristics of the students (the first survey). Means and standard deviations on the individual characteristics variables are presented in Table 5.

The means range from 3.32 to 4.03 indicating that students scored above midpoint on all the scales. There were no significant differences on the individual characteristics variables across courses. It appears that collaborative learning was not a new learning method for them. Students indicated their familiarity with using Internet for gaining resources, although their experience on communicating via text-based medium were quite varied (indicated by the high standard deviation). The results show that students' prior knowledge also vary substantially. The influence of the individual characteristics on the aspects of collaborative learning will be discussed later on.

\section{Table 5}

Means and standard deviations of variables in individual characteristics

\begin{tabular}{lccc}
\hline Variable & $\mathrm{n}$ & $\mathrm{M}$ & $\mathrm{SD}$ \\
\hline Attitude towards collaboration & 112 & 3.62 & .49 \\
Group activity & 112 & 3.83 & .57 \\
Perceived text-based communication & 110 & 3.46 & .70 \\
Prior knowledge & 112 & 3.32 & .86 \\
Opinion on using Internet & 112 & 4.03 & .55 \\
\hline
\end{tabular}

Note. Unit of analysis is the individual mean. The scale is ranging from 1 to 5 , where $1=$ strongly disagree, and $5=$ strongly agree $(3=$ neutral $)$

Not all students respond to our survey completely, $50 \%$ students replied once, $25 \%$ replied twice and 25\% replied all the surveys. However, there were no significant differences between students who reply either once, twice or all surveys on the variables of individual characteristics (all $p \mathrm{~s}$ $>.05)$.

\section{Students' experiences with collaborative learning}

In order to analyse students' experiences with collaborative learning the group means were taken as the unit of analysis, because students worked in groups and interacted with each other. Table 6 provides the group means and standard deviations with respect to the students' experiences with collaborative learning during and after the course.

\section{Table 6}

Means and standard deviations of variables in collaborative learning

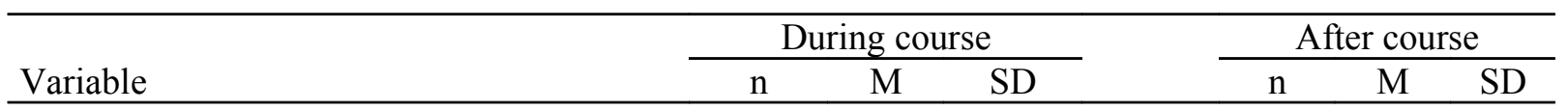




\begin{tabular}{lllllll}
\hline Monitoring working procedure & 26 & 2.56 & .86 & 32 & 2.87 & .64 \\
Participation & 26 & 3.31 & .85 & 32 & 3.29 & .69 \\
Monitoring group progress & 25 & 2.33 & .69 & 32 & 2.64 & .63 \\
Giving feedback & 25 & 3.81 & .73 & 32 & 3.97 & .44 \\
Helping each other & 25 & 3.40 & .76 & 32 & 3.39 & .58 \\
Need to be monitored & 25 & 3.21 & .64 & 31 & 3.31 & .39 \\
Team development & 26 & 3.47 & .59 & 32 & 3.39 & .63 \\
Task strategy & 26 & 3.36 & .73 & 32 & 3.37 & .62 \\
Intra-group conflict & 26 & 2.18 & .44 & 32 & 2.25 & .49 \\
\hline
\end{tabular}

Note. Unit of analysis is the group mean. The scale is ranging from 1 to 5 , where $1=$ strongly disagree, and $5=$ strongly agree $(3=$ neutral $)$

The means range from 2.18 to 3.81 during the course and from 2.25 to 3.97 after the course. No extreme scores were found. The lowest score during and after the course was on the variable Intragroup Conflict. This indicates that there have been no serious conflicts between group members while learning collaboratively. On almost all the other variables the mean is above the midpoint. It can be concluded that students have quite positive experience with collaborative learning.

Further analysis was conducted to examine whether the students' experiences with collaborative learning differed during and after the course. A paired sample $t$ test was used to examine students' experiences with collaborative learning during the course as compared to after the course. However, only 23 groups had completed the questionnaires for the second and the third survey. Results reveal that the variable Monitoring Working Procedure reached statistically significance $(t(22)=-3.58, p=$. 002) in the sense that students experienced monitoring working procedures during the course. So, students paid more attention on monitoring their working procedures in the second half of the course.

In addition, significant differences at a $10 \%$ level were found on the scales Giving Feedback $(t(22)=-1.92, p=.07)$ and Need to be Monitored $(t(21)=-1.94, p=.07)$. So, it seems that students gave more feedback to each other and that they needed more monitoring on group processes in the second half of the course.

Kruskal-Wallis analyses were used to compare across the five courses. This non-parametric analysis was used because, using groups as units of analysis, we had a rather small number of observations within each course. Results reveal that students in the five courses differed significantly on Monitoring Working Procedure $(\chi 2=17.93, \mathrm{df}=3, p<0.001)$, on Team Development $(\chi 2=8.05$, $\mathrm{df}=3, p<0.05)$, and on Intra-group Conflict $(\chi 2=14.23, \mathrm{df}=3, p<0.01)$ during the course. After the course a significant difference was found on Monitoring Working Procedure $(\chi 2=18.81, \mathrm{df}=4, p$ $<0.01)$. When we take a closer look at the mean scores across the five courses, the Management Science course had the lowest means on these variables. This course employed the largest group size (see Table 4) and requested student to submit an individual product. Hence, group size and type of product might be important elements of asynchronous CSCL environments that influence the collaboration process. 


\section{Students' satisfaction with collaborative learning}

Table 7 contains the group means and standard deviations on the satisfaction variables. The means range from 3.31 to 3.97 . These results indicate that the average scores for all satisfaction variables are above the midpoint. This means that students in general were quite satisfied with learning collaboratively in an asynchronous CSCL environment.

Table 7

Means and standard deviations of variables in satisfaction with collaborative learning

\begin{tabular}{lccc}
\hline Variable & $\mathrm{N}$ & $\mathrm{M}$ & $\mathrm{SD}$ \\
\hline Satisfaction with other group members & 32 & 3.52 & .53 \\
Satisfaction with learning in group & 32 & 3.81 & .66 \\
Satisfaction with working in group & 32 & 3.31 & .31 \\
Satisfaction with final product & 32 & 3.97 & .64 \\
\hline
\end{tabular}

Note. Unit of analysis is the group mean. The scale is ranging from 1 to 5 , where $1=$ strongly disagree, and $5=$ strongly agree $(3=$ neutral $)$

\section{Individual and course characteristics that influence aspects of collaborative learning}

In order to answer the questions concerning the influence of individual and course characteristics on aspects of collaborative learning and the influence of collaborative learning aspects on satisfaction, regression analyses were conducted. As the number of potential predictors in the regression equations would be very large in comparison to the number of observations, a factor analysis was conducted to reduce the number of variables to be used in the regression analysis.

Using principal axis factoring with oblique rotation, the five variables in individual characteristics produced a two factor solutions explaining $70 \%$ of the total variance (see Table 8 ). Only variables with a factor loading greater than 0.4 are shown. Factor 1 was labelled as Perceived Technology and factor 2 as Attitude Towards Group Work.

\section{Table 8}

Factor loadings of variables in individual characteristics

\begin{tabular}{lcc}
\hline & \multicolumn{2}{c}{ Factor } \\
\cline { 2 - 3 } Variable & 1 & 2 \\
\hline Attitude towards collaboration & - & .429 \\
Group activity & - & .782 \\
Perceived text-based communication & .849 & - \\
Prior knowledge & - & - \\
Opinion on using Internet & .522 & - \\
\hline
\end{tabular}

We conducted two separate factor analyses on the collaborative learning variables respectively on the data during and after the course in order to see whether our variables in the second and the third 
survey have similar loading factor patterns. Many of the variables loaded on the same dimension; however few did not. In the second survey, one variable was loading below .40 on the appropriate dimension. In the third survey, all of the variables were loading above .40. Next, the variable Giving Feedback which had a weak loading was excluded and the factor analyses on each separate survey were re-run. A three-factor solution seems the best for both the data during and after the course. The pattern of loadings was relatively similar. Table 9 displays the results. Only variables with a factor loading greater than 0.4 are shown. 
Table 9

Factor loadings of variables in collaborative learning

\begin{tabular}{lccc}
\hline & \multicolumn{3}{c}{ Factor } \\
\cline { 2 - 4 } Variable & 1 & 2 & 3 \\
\hline During the course & .566 & .676 & .570 \\
Monitoring working procedure & .864 & - & .413 \\
Participation & - & .886 & - \\
Monitoring group progress & - & - & .464 \\
Helping each other & - & - & .754 \\
Need to be monitored & .957 & - & .456 \\
Team development & .871 & - & - \\
Task strategy & .628 & - & - \\
Intra-group conflict & & & \\
& & & - \\
After the course & - & .937 & .467 \\
Monitoring working procedure & .921 & - & - \\
Participation & - & .837 & .488 \\
Monitoring group progress & - & - & .412 \\
Helping each other & - & - & - \\
Need to be monitored & .876 & - & - \\
Team development & .804 & - & \\
Task strategy & .776 & - & \\
Intra-group conflict & &
\end{tabular}

The second measurement (during the course) accounted for $72 \%$ of the variance in the data and the third survey measurement (after the course) accounted for $79 \%$ of the variance in the data. The first factor corresponds to group cohesion (COHES), factor two to the regulation of group processes (PROCESS) and factor three to group support (SUPPORT). These three factors were used as collaborative learning aspects for the regression analysis.

Regression analyses with attitude towards group work, perceived technology, group size and type of product as independent variables and the regulation of group processes, group cohesion and group support as dependent variables were conducted using the backward elimination method. These explorative analyses yielded only a single model where a significant proportion of variation in the dependent variable could be explained: the model containing the regulation of group processes (PROCESS) as dependent variable and type of product (PRODUCT - with values 0 in case of a group product and 1 in case of an individual product) as independent variable $\left(\mathrm{F}(1,45)=32.72, p<0.001, \mathrm{R}^{2}\right.$ $=0.422$ ). This OLS regression analysis ignores the fact that individuals were nested within study groups. A regression model that takes this nested structure into account is a multilevel model known as the random coefficient model. Using multilevel analysis to re-analyse the regression model we found with OLS regression yielded the following equation (with associated standard errors between brackets): PROCESS $=0.548(0.146)-1.248(0.124)$ PRODUCT . 
This finding suggests that requiring a group product tends to stimulate group members to regulate their group during collaborative learning.

\section{Aspects of collaborative learning that influence satisfaction}

A regression analysis of group cohesion (COHES), group support (SUPPORT) and the regulation of group processes (PROCESS) on satisfaction with other group members (SATOTHER) using the backward elimination method resulted in a regression model that retained group cohesion and group support as statistically significant predictors of satisfaction with other group members, $\mathrm{F}(2,44)=13.852, p<.001, \mathrm{R}^{2}=0.386$. Again, OLS regression analysis ignores the fact that individual subjects were embedded within study groups, yielding dependency among scores. Using multilevel analysis to test the model we had found with OLS regression, we found a result quite similar to that which was obtained with ordinary regression analysis. The random intercept model that was returned by the multilevel analysis was (with SE's reported between brackets): SATOTHER $=3.63(0.08)+$ $0.29(0.08)$ COHES +0.18 (.09) SUPPORT, showing both group cohesion and group support to be significant predictors of satisfaction with others.

Similarly, a regression analysis of group cohesion, group support and the regulation of group process on satisfaction with learning in group (SATLEARN) using the same backward elimination method yielded group cohesion and group support as statistically significant predictors of satisfaction with learning in group, $\mathrm{F}(2,44)=31.137, p<.001, \mathrm{R}^{2}=0.586$. Multilevel analysis returned the following model: SATLEARN $=3.89(0.08)+0.39(0.07)$ COHES $+0.17(0.07)$ SUPPORT, showing both group cohesion and group support to be significant predictors of satisfaction with learning in group.

A third regression analysis of group cohesion, group support and the regulation of group process on satisfaction with working in group (SATGROUP) using backward elimination resulted in a regression model that retained group cohesion and the regulation of group processes as statistically significant predictors of satisfaction with working in group, $\mathrm{F}(2,44)=10.134, p<.001, \mathrm{R}^{2}=0.315$. Multilevel analysis returned the following model: SATWORK $=3.40(0.05)+0.22(0.05)$ COHES 0.13 (0.05) PROCESS, showing both group cohesion and the regulation of group processes to be significant predictors of satisfaction with working in group.

Finally, a regression analysis of group cohesion, group support and the regulation of group processes on satisfaction with final product (SATPROD) using the same backward elimination method resulted in a regression model that only retained group cohesion as statistically significant predictor of satisfaction with final product, $\mathrm{F}(1,45)=15.914, p<.001, \mathrm{R}^{2}=0.261$. Multilevel analysis returned the following model: SATPROD $=3.96(0.14)+0.46(0.10)$ COHES, showing only group cohesion to be a significant predictor of satisfaction with final product.

Together, these analyses suggest that group cohesion is an important aspect of collaborative learning that influences students' satisfaction with collaborative learning. 
Messages from one group from the Law course were analysed to get insight into how group members collaborated when they accomplished the task. The content analysis was divided into two parts: part one contains data gathered from beginning the course to survey 2 (period 1) and part two contains data collected from survey 2 to the end of the course (period 2).

In the first period, each group members was asked to complete the task individually. Then all group members had to comment on the work of the others and they had to take the comments on their own work into account. In the second period, group members were asked to prepare joint products. All group members had to collaborate to write, discuss and comment the products.

To arrive at a balanced comparison between the number of units occurring in a category during the first period and the number of times these units were mentioned during the second period, percentages of units are compared.

When the course ended, students' messages were obtained from the server. The transcript corpus consists of 393 messages containing over 1009 units. In average, each group member posted 98 messages. Table 10 shows frequency and percentage of dimensions posted by students during period 1 and period 2.

\section{Table 10}

Number and percentage of units in all dimensions posted by students during period 1 and period 2

\begin{tabular}{lrr}
\hline Dimension & Period 1 & Period 2 \\
\hline Regulation & $60(20)$ & $158(22)$ \\
Consensus & $28(10)$ & $92(13)$ \\
Conflict & $4(1)$ & $8(1)$ \\
Content & $117(40)$ & $284(39)$ \\
Social & $20(7)$ & $37(5)$ \\
Technology & $14(5)$ & $40(6)$ \\
\hline
\end{tabular}

Note: values shown are numbers of units; percentages are in parentheses

The overall amount of messages increased as the course progressed from 107 messages (293 units) during the first period to 286 messages (716 units) during the second period. However, the percentages of units of all dimensions remain quite stable over both periods of the course. This result might suggest that group members need some time to adjust themselves with working together to complete a task. In order to get more insight in the collaboration process, we analysed the six dimensions into detail: Regulation, Consensus, Conflict, Content, Social, and Technology. Table 11 gives an overview of the number of units and the percentages of the different categories within the six dimensions. 


\section{Table 11}

Number and percentage of units in dimensions: Regulation, Consensus, Conflict, Content, Social and Technology

\begin{tabular}{lrr}
\hline Dimension & Period 1 & Period 2 \\
Category & & \\
\hline Regulation & $8(13)$ & $4(3)$ \\
Orientation & $12(20)$ & $28(18)$ \\
Plan & $1(2)$ & $4(3)$ \\
Reflection & $1(2)$ & $2(1)$ \\
Monitoring general & $28(46)$ & $105(66)$ \\
Monitoring working procedure & $3(5)$ & $12(7)$ \\
Monitoring working progress & $7(12)$ & $3(2)$ \\
$\quad$ Monitoring participation & & \\
Consensus & $22(79)$ & $65(71)$ \\
Reach consensus & $6(21)$ & $27(29)$ \\
$\quad$ Try to reach consensus & & $8(100)$ \\
\hline Conflict & $4(100)$ & $49(17)$ \\
Conflict & & $103(37)$ \\
\hline Content & $18(15)$ & $49(17)$ \\
Ask & $32(27)$ & $72(25)$ \\
Explain & $27(23)$ & $10(4)$ \\
Argue & $37(32)$ & $2(5)$ \\
Product & $3(3)$ & $24(65)$ \\
External resources & & $11(30)$ \\
\hline Social & $0(0)$ & $40(100)$ \\
Negative emotion & $15(75)$ &
\end{tabular}

Note: values shown are numbers of units; percentages are in parentheses

In the Regulation dimension Monitoring Working Procedure increased sharply from the first period ( $46 \%$ ) to the second period ( $66 \%$ ), Orientation declined from $13 \%$ in the period 1 to $3 \%$ in the period 2, followed by the Monitoring Participation category which also dropped dramatically from $12 \%$ during the first period to $2 \%$ in the second period. The increase of Monitoring Working Procedure indicates that group members paid more attention to monitor their working procedure during the second half of the course. Whereas the decline of Monitoring Participation might suggest that group members felt more responsibility for individual contribution after a period of time. A slight increase was found at Reflection, and Monitoring Working Progress, whereas Plan and Monitoring General remained almost the same throughout the course.

Within the Consensus dimension the percentages increased in the second period. Try to reach consensus rose from $19 \%$ in the first period to $27 \%$ in the second period. Also in the Conflict dimension, the number of units inclined twice in the second period than in the first period. The results 
from both dimensions indicate that in the second period the group took more difference perspectives and opinions into considerations.

The results in the Content dimension were varied. For instance, Explaining increased from $27 \%$ to $37 \%$, whereas Product decreased from $32 \%$ to $25 \%$. Very slight increases were found on Ask and Share External Resources. These results imply that group members were more active in gaining knowledge domain in the second period than in the first period of the course.

In the Social dimension, the results show that students made several comments in the Off-task category and exhibited a very small portion of Negative Emotion. The highest percentage was reached by Positive Emotion. This result might indicate that students showed their positive feelings and encouraged each other during collaborative learning.

The last dimension is Technology. The percentage of this dimension remained stable during both periods. This stable percentage reflected the students' familiarity with communication via discussion group.

\section{Discussion and conclusion}

The aim of this study was to explore students' experiences and satisfaction with collaborative learning in asynchronous CSCL environments. In order to have a good grip of crucial aspects during collaborative learning, the influence of individual and course characteristics on aspects of collaborative learning and the influence of the aspects of collaborative learning on satisfaction was determined. Also, students' messages from one group were analysed to gain more insight in how group members collaborate while working on a task.

The first issue examined was students' experiences with collaborative learning as a result of participating in the courses with a collaborative learning method. In general students show quite positive experiences with working in a CSCL environment both during and after the course. Only on the variable Monitoring Working Procedure a significant difference was found between the first and the second half of the course. In the second half of the course students paid more attention to the procedures they had to follow to accomplish the task. It might indicate that group members' involvement in regulating group processes might take some time to occur and does not happen at the beginning of the collaboration automatically. Besides, this may be due to the fact that working procedures must be more efficient in the second half of the course, because it was not allowed to exceed the deadline for accomplishing the task. Moreover, the scores on variables in collaborative learning, namely Monitoring Working Procedure and Monitoring Group Progress, were lower than on the other variables both during and after the course. Students seemed not to pay much attention to monitor their collaboration process from the beginning. Hence, it is suggested to scaffold group members in regulating group processes from the beginning of their collaboration.

The second issue investigated was whether students were satisfied with working and learning in an asynchronous CSCL environment. Consistent with previous studies (Bures, Abrami, \& Amundsen, 
2000; Harasim, 2001), our results also indicate that students were in general satisfied with working and learning in an asynchronous CSCL environment. On all the satisfaction variables the students mean scores were above the midpoint of the scale. Distance learning is often promoted to give flexibility for learners to manage their individual learning. Collaborative learning, however, limits the flexibility of distance learners because it creates interdependence between the group members. However, despite the fact that distance learners have less freedom in an asynchronous CSCL environment, the results in this study show that students were quite pleased with learning this way.

The third issue examined whether individual and course characteristics influenced the collaboration process. It was expected that small-groups as well as a task which requires a group product would stimulate student involvement in collaborative learning. The result of the present study indicates that the type of product influences the regulation of group processes. This finding shows that a group product stimulates students to regulate their group processes because it involves all group members proceeding the task (Cohen, 1994; Johnson et al., 1994). Thus, requiring a group product not only enhance students to gain subject knowledge but also stimulate students to develop group skills such as orienting, planning and monitoring. Although, the result of this study does not support the expectation that small group size stimulate group processes more than large groups, there is an indication that participants from the course that used large groups (7 group members each group) scored lower on the experiences with collaborative learning than the participants from the other courses. So, there is some evidence to conclude that the use of small groups is recommendable above larger groups. In addition, other studies (Hammond, 2000; Kaye, 1992; Wegerif, 1998) also recommend using small groups rather than large groups.

The fourth issues examined aspects of collaborative learning which influence students' satisfaction. The results reveal that group cohesion is an important aspect that influences students' satisfaction. This finding is congruence with the work of Johnson et al. (1994); they also underline the importance of group cohesion during collaboration to keep the group work together. Another finding is that the regulation of group processes has a negative influence on satisfaction with working in a group. This finding contradicts with the result from Gillies (2003). In his study he reported that unstructured group processes led to students became less positive about their group experiences. A possible explanation for this finding that we should take into account is that the participants were different. Our participants were distance learners who are adults and have to manage their time to study as well as their time to work Although our finding shows that the regulation of group processes influences negatively on satisfaction with working in a group, we argue that the regulation of group processes is needed during collaborative learning and is considered to be supportive in the learning process. Lack of the regulation of group processes may cause a group loss of control in achieving their goal.

The fifth issue examined the collaborative activities within one group. The group members' discourse while completing a task were analysed. In general, most of the group communications 
discussed the learning content. Activities such as asking, arguing, explaining, and providing extra resources dominated more than regulatory activities such as planning, monitoring and reflecting. These findings are in line with other results of studies on collaborative learning in asynchronous CSCL environments (Veerman, 2000; Veldhuis-Diermanse, 2002). The technology and social dimension had the lowest percentage numbers throughout the course. It implied that students were quite familiar with communication via the computer and indicated that group members did not spend much time to comment on unrelated task. Although, these findings indicated that learning in an asynchronous CSCL-environment focused more at completing the task than on other activities (such as talking about social life). It is important to notice that we analysed only discourse from one group.

Two limitations of this study need to be acknowledged. One limitation of this study is the sample size. Not all participants responded to our questionnaires. The number of participants in the second and third survey was among other things reduced because of leaving the course and of time pressure. Another limitation of this study was that we focussed only partly on actual students behaviour. Due to these limitations, the results of this study should be interpreted with caution.

Finally, the results of this study have several important implications for practice. First, it is suggested to set tasks requiring a high level of collaboration; for instance tasks which require a group product. Second, the use of small groups instead of large groups is recommendable. Those two recommendations are necessary conditions to start interaction in the collaboration process. Third, in order to maintain group cohesion we might consider asking students to reflect on their group processes. Hence, all group members should have the opportunity to reflect on their group activities and on gained knowledge in order to improve their group performance. Fourth, the less experience of the regulation of group processes might be tackled by providing specific guidelines on how to regulate the group. Besides reflection on group processes can also be used to improve the regulation of group processes. Finally, it is recommended to use asynchronous CSCL environments as a medium to support collaborative learning form for distance education, because collaborative learning is seen as a didactical approach that stimulates 'new learning'. 